\title{
Hematobiological Profile of Patients with Chronic Myeloid Leukemia at the Diagnosis in Yaoundé: A Cross-Sectional Study
}

\author{
Annie Prudence Bisso Ngono1,2, Prisca Angandji Tipane, 13 , Sylvain Raoul Simeni Njonnou ${ }^{4,5^{*}}$, \\ Aimée Tiodoung Timnou6, Anne Juliette Flora Sango²,7, Paul Ndom 6,8,9, \\ Claude Tayou Tagny1,10, Dora Mbanya1,10,11
}

${ }^{1}$ Department of Microbiology, Parasitology, Hematology and Infectious Diseases, Faculty of Medicine and Biomedical Sciences, University of Yaoundé I, Yaoundé, Cameroon

${ }^{2}$ Yaoundé Central Hospital, Yaoundé, Cameroon

${ }^{3}$ Yaoundé Jamot's Hospital, Yaoundé, Cameroon

${ }^{4}$ Department of Internal Medicine and Specialties, Faculty of Medicine and Pharmaceutical Sciences, University of Dschang, Dschang, Cameroon

${ }^{5}$ Dschang District Hospital, Dschang, Cameroon

${ }^{6}$ Department of Internal Medicine and Specialties, Faculty of Medicine and Biomedical Sciences, University of Yaoundé I, Yaoundé, Cameroon

${ }^{7}$ Department of Internal Medicine and Pediatrics, Faculty of Health Sciences, Medicine and Biomedical Sciences, University of Buea, Buea, Cameroon

${ }^{8}$ Yaoundé General Hospital, Yaoundé, Cameroon

${ }^{9}$ Solidarité Chimiothérapie (SOCHIMIO), Yaoundé, Cameroon

${ }^{10}$ Yaounde University Teaching Hospital, Yaoundé, Cameroon

${ }^{11}$ National Center for Blood Transfusion, Yaoundé, Cameroon

Email: *raoulsims@yahoo.fr

How to cite this paper: Bisso Ngono, A.P., Angandji Tipane, P., Simeni Njonnou, S.R., Tiodoung Timnou, A., Flora Sango, A.J., Ndom, P., Tayou Tagny, C. and Mbanya, D. (2020) Hematobiological Profile of Patients with Chronic Myeloid Leukemia at the Diagnosis in Yaoundé: A Cross-Sectional Study. Open Journal of Blood Diseases, 10, 110-123.

https://doi.org/10.4236/ojbd.2020.104013

Received: October 18, 2020

Accepted: December 20, 2020

Published: December 23, 2020

\begin{abstract}
Background: Chronic Myeloid Leukemia (CML) is a myeloproliferative blood neoplasia, characterized by the presence of a translocation between chromosomes 9 and 22 leading to the formation of the Philadelphia chromosome. Data on the biological profile of patients with CML at diagnosis are still lacking in sub-Saharan Africa, particularly in Cameroon. Methods: A cross-sectional study was carried out from January 2001 to July 2016 among patients recently diagnosed with CML at the Yaounde University Teaching Hospital, the Yaoundé Central Hospital and the Yaoundé General Hospital. Analyzed variables included socio-demographic, clinical presentation, the diagnosis means, biological parameters (hematological and biochemical). Sampling was consecutive. Results: We included 132 (76 males) patients with CML with a median age of 39.2 years at diagnosis. The $31-45$ years age group was the most represented, with $40.9 \%$ of the study population. A risk
\end{abstract}


Copyright $\odot 2020$ by author(s) and Scientific Research Publishing Inc. This work is licensed under the Creative Commons Attribution International License (CC BY 4.0).

http://creativecommons.org/licenses/by/4.0/

Open Access factor was found in only 5 (3.8\%) of patients. Clinical manifestations were recorded in only 27 (20.45\%) patients, with fatigue being the commonest (10.6\%). Almost all patients $(128,96.9 \%)$ have performed the karyotype while 22 (16.7\%) have performed fluorescence in situ hybridization (FISH) and 4 (3.0\%) the PCR. At diagnosis, $66 \%$ of the patients were in the chronic phase (CP), $11.3 \%$ in accelerated phase (AP), and $22.7 \%$ in blast crisis (BC). All patients presented hyperleukocytosis, with a white blood cell mean of $128,362 / \mathrm{mm}^{3}$. Anemia was common (77.3\%), usually moderate (61.4\%). Thrombocytopenia was rare $(8.3 \%)$, as far as basophilia (1.2\%). Among those patients, mean values of creatinine, Glutamic pyruvate transaminase (GPT) and glycemia were normal while activated partial thromboplastin time (APTT), prothrombin time (PT), plasma uric acid level, gamma glutamic transferase (GGT), lactate dehydrogenase (LDH), and inflammatory parameters (ESR and CRP) were increased. Conclusion: Patients with CML presented at their diagnosis hyperleukocytosis and anemia as hematological clues. Other biological anomalies include increased signs of cellular destruction (plasma uric acid level, LDH), coagulation perturbation and inflammatory syndrome. The chronic phase of the disease was common.

\section{Keywords}

Chronic Myeloid Leukemia, Biological Clues at Diagnosis, Sub-Saharan Africa

\section{Background}

Chronic myeloid leukemia (CML) is a myeloproliferative disorder, as are essential thrombocythaemia (ET), Vasquez's disease (VD), and idiopathic chronic or primary myelofibrosis (PMF). It is characterized by the presence of a balanced translocation between chromosomes 9 and 22 (Philadelphia chromosome) resulting in the formation of the BCR-ABL1 fusion protein, with highly dysregulated tyrosine kinase activity [1] [2].

CML represents $15 \%$ - $20 \%$ of adult leukemia [3]. It is a malignant hematological malignancy for which epidemiological data are still poorly defined [4]. In France, CML has an annual incidence of almost 1 to 2 new cases per 100,000 population, with a discreet male predominance [5]. This incidence is comparable to the average of the countries of central and northern Europe [4] [6]. In the United States, the incidence of CML was 1.75/100,000 people per year and increased with age [7]. The American Cancer Society (ACS) estimates that 1090 deaths from CML will occur in 2018, 620 in men, and 470 in women [8]. CML occurs at any age, but more commonly in adult males 30 to 60 years old. There is no proven geographic or ethnic specificity even though Caucasians seem more affected than black individuals. Epidemiological data on patients with CML are rare in Sub-Saharan Africa (SSA). Most of the studies conducted on this topic focused on survival in patients treated with Imatinib [9]-[13]. Boma et al., in the early 2000s, identified splenomegaly and hepatomegaly as poor survival risk fac- 
tors [13]. In Ivory Coast, Silué et al. on the other side, identified additional chromosomal abnormalities, hepatomegaly, fever, bone pain, lymphadenopathies, poor general condition, high Sokal index, eosinophilia $>5 \%$ and circulating blasts as poor survival risk factors [14].

Only few studies have been performed on CML in Cameroon. They focused on epidemiological data (sociodemographic characteristics, comorbidities) and prognosis factors of treated patients [15] [16] [17] [18] [19]. To the best of our knowledge, there is no data on the biological presentation of patients with CML at diagnosis. It was therefore important for us to describe the biological profile of this population.

\section{Methods}

\subsection{Study Design and Setting}

We conducted a cross-sectional study in the Hematology and blood transfusion department of the Yaounde University Teaching Hospital, the Hematology department of the Yaounde Central Hospital and the Oncology department of the Yaoundé General Hospital from January 2001 to July 2016. Yaoundé General Hospital and Yaoundé University Teaching Hospital are tertiary hospitals in Yaoundé, the capital city of Cameroon (SSA), while Yaoundé Central Hospital is a secondary health facility. They have a catchment population of about 2 million inhabitants. Health insurance coverage is almost inexistent and the minimum wage is 64.3 USD per month [20].

Patients were retrospectively recruited from January 2001 to December 2015, while the prospective phase of the study took place from January to July 2016.

\subsection{Variables and Measurements}

- Inclusion criteria: Were included files of all subjects, with CML (diagnosis made by cytogenetic and/or molecular biology) and presenting at least at the initial biological workup a full blood count.

- Exclusion criteria: Were excluded patients with an incomplete file (particularly diagnosis means and biological workup).

The cytogenetic and molecular studies were performed by Cerba laboratories in Paris. Cytogenetic and molecular responses were evaluated according to the criteria of European Leukemia Net (ELN) 2013.

- Sample size: the sampling was exhaustive and consecutive.

- Variable and measurements:

Using a standardized questionnaire, we collected data on socio-demography (age, gender, and profession), clinical presentation (risk factors, signs and symptoms) in patients' records, or through an interview (for the patients recruited in the prospective phase). Biological parameters included: diagnosis means (Karyotype and molecular studies). Hematological workup included at least full blood count, looking for anemia, leukocytosis, basophilia or thrombocytopenia. Blood film and bone marrow aspiration results were also recorded. 
Other biological exams were biochemical (transaminase, serum creatinine, fasting blood sugar, uricemia, GGT, LDH, CRP and ESR).

\subsection{Statistical Analysis}

Data have been analyzed using Statistical Package for Social Sciences (SSPS Inc, Chicago, Illinois, USA) V.20.0 and EPI-INFO V.3.5 software. Quantitative data are presented as means and qualitative data are presented as frequencies and percentages.

\section{Results}

Participants: We included 132 (76 males) patients with CML with a mean age of 39.2 years at diagnosis. The most frequent age group was 31 to 45 years with $54(40.9 \%)$ patients (Figure 1). The patients were mainly $(74 ; 56.1 \%)$ from the West region, followed by North-West with 24 (18.2\%). Unemployed were the most numerous (26.5\%), followed by private-sector workers (25\%) and students (15.2\%). The occupation was not mentioned in $21.2 \%$.

Risk factors for CML were found in 5 (3.8\%) patients, with chronic pesticides use, insecticide use, chronic exposition to paintings and hydrocarbons exposition been the main risk factors.

Diagnosis: The diagnosis was performed on standard karyotype for 108 (81.8\%) patients. Molecular testings (FISH and Rt-PCR) were respectively performed in $22(22.7 \%)$ and $6(4.5 \%)$ patients. Two patients had positive karyotype and FISH at the same time, while two others had positive karyotype and Rt-PCR. Of the 97 patients whom disease classification was possible, 64 (66\%), $11(11.3 \%)$ and $22(22.7 \%)$ patients were in chronic, accelerated, or blast phase at diagnosis, respectively. Symptoms were recorded in only 27 patients with fatigue found in 14 (51.5\%), abdominal discomfort in $5(18.5 \%)$ as well as night sweats. Splenomegaly was mentioned in 60 (45.5\%) without any other information (Table 1).

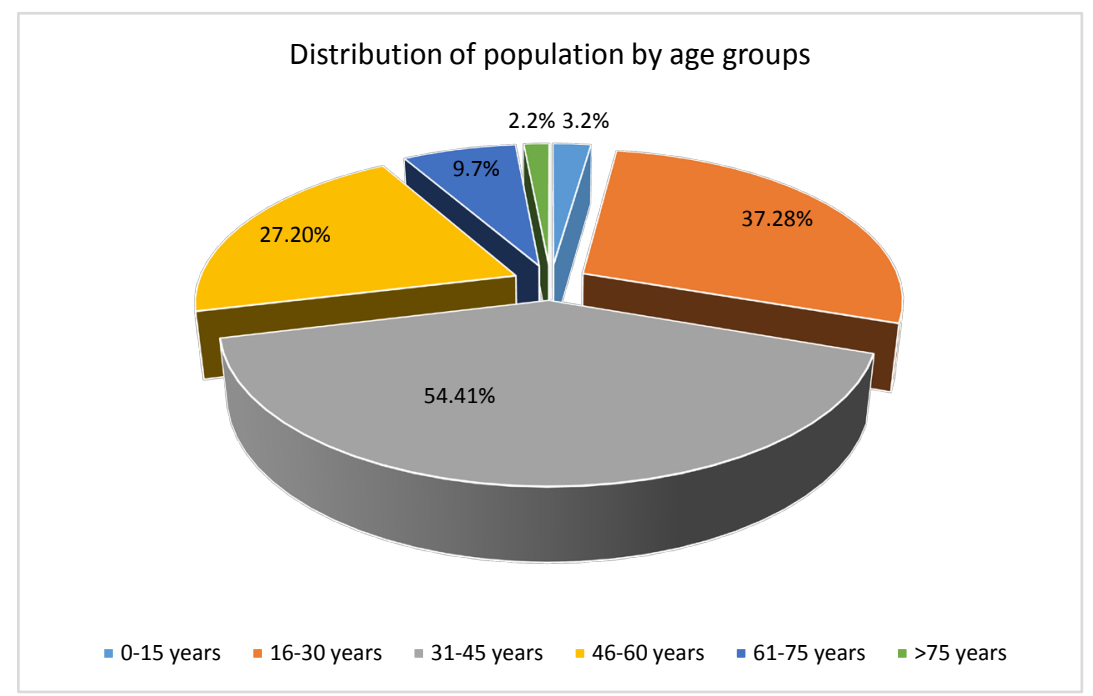

Figure 1. Distribution of the population by age groups. 
Table 1. Study population sociodemographic and clinical characteristics.

\begin{tabular}{|c|c|c|}
\hline Variables & Number (n) & Percentage (\%) \\
\hline \multicolumn{3}{|l|}{ Gender } \\
\hline Male & 76 & 57.6 \\
\hline Female & 56 & 42.4 \\
\hline \multicolumn{3}{|l|}{ Region } \\
\hline Adamaoua & 2 & 1.5 \\
\hline Centre & 9 & 6.8 \\
\hline East & 0 & 0 \\
\hline Far-North & 0 & 0 \\
\hline Littoral & 8 & 6.1 \\
\hline North & 10 & 7.6 \\
\hline North West & 24 & 18.2 \\
\hline South & 3 & 2.3 \\
\hline South West & 2 & 1.5 \\
\hline West & 74 & 56.1 \\
\hline \multicolumn{3}{|l|}{ Occupation } \\
\hline Unemployed & 35 & 26.5 \\
\hline Farmer & 1 & 0.8 \\
\hline Trader & 5 & 3.8 \\
\hline Civil servant & 10 & 7.6 \\
\hline Private sector worker & 33 & 25.0 \\
\hline Student & 20 & 15.2 \\
\hline Missing data & 28 & 21.2 \\
\hline \multicolumn{3}{|l|}{ Clinical characteristics } \\
\hline Abdominal mass & $3 / 27$ & 11.1 \\
\hline Night sweats & $5 / 27$ & 18.5 \\
\hline Fatigue & $14 / 27$ & 51.8 \\
\hline Abdominal discomfort & $5 / 27$ & 18.5 \\
\hline Splenomegaly & $60 / 132$ & 45,4 \\
\hline \multicolumn{3}{|l|}{ Diagnosis exams performed } \\
\hline Full blood count & 132 & 100 \\
\hline Blood film & 100 & 75.8 \\
\hline Bone marrow aspiration & 10 & 7.6 \\
\hline Standard karyotype & 128 & 97 \\
\hline FISH & 22 & 16.7 \\
\hline RT-PCR & 06 & 4.5 \\
\hline
\end{tabular}


Hematological data: All patients presented the marked leukocytosis involving the granulocytic lineage, associated with early myeloid cells. The $t(9 ; 22)$ and/or bcr-abl transcript was found in all patients. Leukocytosis ranged from 27,988 to $588,700 / \mathrm{mm}^{3}$ with a mean value of $128,367 \pm 23,000 / \mathrm{mm}^{3}$. Most of the patients $(60.6 \%)$ had their leukocyte count between 100,000 and $200,000 / \mathrm{mm}^{3}$. Only $5(3.8 \%)$ patients had leukocytosis values of more than $500,000 / \mathrm{mm}^{3}$ (Figure 2).

Almost all (86.4\%) of patients were anemic. Hemoglobin value ranged from 05 to 15 with a mean value of $9.9 \pm 2 \mathrm{~g} / \mathrm{dL}$ (Figure 3 ). Most of the patients (42.4\%) had a hemoglobin level between 9 and $10 \mathrm{~g} / \mathrm{dL}$. The anemia was moderate for $61.4 \%$ and severe for $5.3 \%$ of the study group.

Platelet count ranged from 42,000 to $2,252,000 / \mathrm{mm}^{3}$ with a mean value of $336,769 \pm 280,000 / \mathrm{mm}^{3}$. Most of patients (42.4\%) had platelets count between 200,000 and $400,000 / \mathrm{mm}^{3}$. Normal platelet count was found in $80(60.6 \%)$, while $11(8.3 \%)$ had thrombocytopenia and 41 (31.1\%) patients had thrombocytosis (Figure 4). Only $10(7.6 \%)$ patients had a platelet count greater than $1,000,000 / \mathrm{mm}^{3}$.

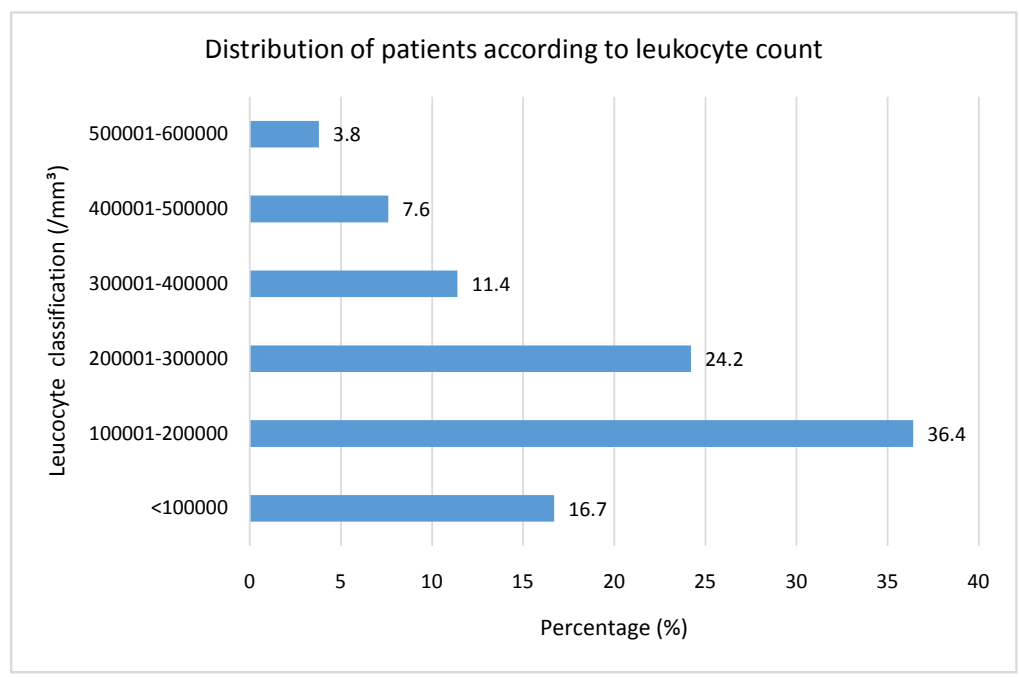

Figure 2. Distribution of patients according to leukocyte count.

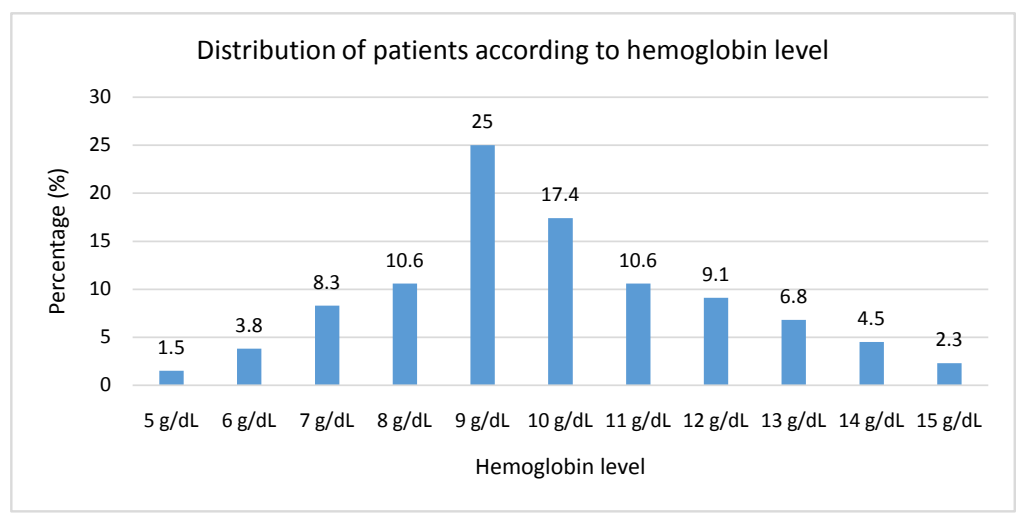

Figure 3. Distribution of patients according to hemoglobin level. 


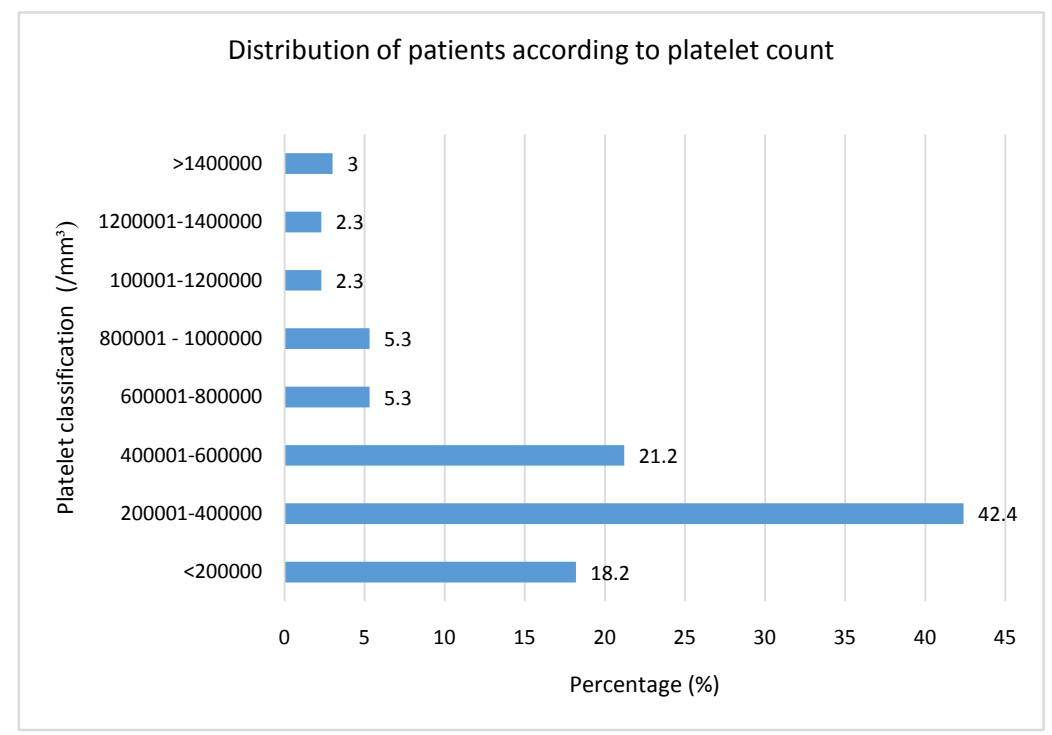

Figure 4. Distribution of patients according to platelet count.

A blood thin-film result was available for only 100 (75.8\%) patients. Only 81 of them had information on basophile percentage. Among this population, 48 (59.3\%) patients had normal values $(<1 \%)$ while $32(39.5 \%)$ and $1(1.2)$ had respectively a basophile percentage between 2 and $20 \%$ and higher than $20 \%$. The basophile mean count was $2800 \pm 4100 / \mathrm{mm}^{3}$. Myeloblast percentage was performed on blood and bone marrow for 88 patients. Thus $56(63.6 \%)$ patients had $<10 \%$ myeloblast, whereas $10(11.4 \%)$ had between $10 \%-20 \%$ myeloblast and 22 (25\%) more than $20 \%$ myeloblasts. The myeloblast mean count was $13,600 \pm$ $17,100 / \mathrm{mm}^{3}$. Among patients who performed standard karyotype, apart from the classical Philadelphia chromosome, some genetic anomalies have been identified in 15 of them. Among them, Philadelphia chromosome duplication (3/132) and Philadelphia chromosome variants (6/132) were the main additional anomalies.

Other biological exams: Other exams have been performed at the diagnosis in our patients. Most of them were biochemical exams. Transaminase, urea, serum creatinine, and fasting blood sugar means were normal. However, APTT (39.7 s, normal value 20.6 - 28.6), PT (15.3 s, normal value 9.8 - 12.5), plasma uric acid (77.1 mg/L, normal value 40 - 60), GGT (107.2 U/L, normal value 10 71), LDH (2809.5 U/L, normal value 15 - 225), ESR (59.4, normal value 1 - 19 $\mathrm{mm} / \mathrm{H})$, and CRP $(232.8 \mathrm{mg} / \mathrm{L}$, normal value $<5 \mathrm{mg} / \mathrm{L})$ means were increased. Table 2 summarizes the biological exams.

\section{Discussion}

This cross-sectional study aimed to assess the hematobiological profile at diagnosis in a group of patients with CML in a sub-Saharan African setting. This study represents one of the largest databases of patients with CML in SSA. Epidemiology and prognosis factors for CML are already determined in western and 
some sub-Saharan African countries. If epidemiology and prognosis factors are determined for CML in western countries, data is still lacking for the patient's hematobiological profile at diagnosis in the sub-Saharan setting, and particularly in Cameroon [9] [11] [12] [14] [15] [21] [22] [23].

The mean age was 39.2 years (ranging from 11 to 76). It was similar to Chetcha et al. (39 years) in Cameroon, Segbena et al. (40 years) in Togo, Oyekunle et al. (38 years) in Nigeria, Silué et al. (39 years) in Ivory Coast and Mupepe in Democratic Republic of Congo [15] [21] [22] [24] [25]. The lower age at diagnosis of CML in SSA reflects epidemiological data, confirming thus, a lower age in low-and middle-income countries in contrary to high-income countries [26] [27] [28] [29]. We found a male predominance in our study, similarly to Chetcha et al., Koffi et al., Oyekunle et al., Mukiibi et al. [10] [21] [22] [30]. A risk factor for CML was found in 5 (3.8\%) of patients, with the recurrent use of pesticides and insecticides, and work in the field of hydrocarbons being the main risk factors. Risk factors are not usually found in SSA, only Djouadi-Lahlou identified 9 patients (over 1927) with risk factors for CML in Algeria [31].

Table 2. Results of the biological exams.

\begin{tabular}{|c|c|c|}
\hline Variables & Mean & Range \\
\hline \multicolumn{3}{|l|}{ Hematological exam } \\
\hline Leukocyte count & 128,418 & $27,988-588,700$ \\
\hline Hemoglobin & 9.9 & $5-15$ \\
\hline Platelet & 336,769 & $42,000-2,252,000$ \\
\hline Basophile percentage & 2.8 & $0-22$ \\
\hline \multicolumn{3}{|l|}{ Coagulation tests } \\
\hline $\operatorname{APTT}(\mathrm{s})$ & 39.7 & $33-48$ \\
\hline $\mathrm{PT}(\mathrm{s})$ & 15.3 & $14-18$ \\
\hline \multicolumn{3}{|l|}{ Biochemical exams } \\
\hline GPT (U/L) & 36 & $12-139$ \\
\hline Urea (mg/dL) & 30 & $10-100$ \\
\hline Serum creatinine (mg/dL) & 1.2 & $0.6-3.6$ \\
\hline Fasting blood sugar (mg/dL) & 80 & $50-110$ \\
\hline Plasma Uric acid (mg/L) & 77.1 & $13-147$ \\
\hline GGT (U/L) & 107.2 & $20-628$ \\
\hline $\mathrm{LDH}(\mathrm{U} / \mathrm{L})$ & 2809 & $320-7741$ \\
\hline $\operatorname{ESR}(\mathrm{mm} / \mathrm{H})$ & 59.4 & $9-123$ \\
\hline $\mathrm{CRP}(\mathrm{mg} / \mathrm{L})$ & 232.8 & $24-831$ \\
\hline
\end{tabular}


As our study is mostly retrospective, there is a lack of clinical signs. Thereby, symptoms were recorded for only 27 patients and splenomegaly was mentioned in $60(45.5 \%)$ patients. The splenomegaly prevalence is lower than that found by Chetcha et al. (75\%) and Faye et al. (80\%) [9] [16]. The patients in CP of CML were lower $(66 \%)$ in our study population comparing to Chetcha et al. (79\%), Faye et al. (85.5\%), and Gaudong et al. (88\%) findings [9] [12] [21]. We did not find any explanation for these proportions.

Full blood count (FBC), blood film and bone marrow aspiration were respectively performed in $100 \%, 75.8 \%$ and $7.6 \%$ of our patients. If the FBC rate is similar to other studies, the blood film rate is lower than that performed in Algeria [31]. By the same, the bone marrow aspiration rate was very low compared to that performed by Mupepe et al. [25]. Standard karyotype was performed in only $97 \%$ of patients (similarly to most of the studies), while FISH was done in $16.7 \%$ at diagnosis [9] [25] [31]. PCR was performed in 4.5\% of patients. This was higher than Mupepe et al. (0\%) but lower than Djouadi-Lahlou et al. (11\%) and Kueviakoe and al. (100\%) [25] [31] [32].

The leukocyte count ranged from 27,988 to $588,700 / \mathrm{mm}^{3}$, with a mean of $128,367 / \mathrm{mm}^{3}$. Most of the patients (60.6\%) had their leukocyte count between 100,000 and $200,000 / \mathrm{mm}^{3}$. This result was similar to Mupepe et al. findings, where the 100,000 to $300,000 / \mathrm{mm}^{3}$ group accounted for $55.2 \%$ of the population [25]. Mukiibi et al. found almost similar results [30].

Hemoglobin levels ranged from 5 to $15 \mathrm{~g} / \mathrm{dL}$, with a mean of 9.9. Among our population, $86.4 \%$ had anemia. Most of the patients were between 9 and $10 \mathrm{~g} / \mathrm{dL}$. The anemia was moderate for $61.4 \%$ and severe for $5.3 \%$ of the study group. Our data are similar to that of Kueviakoe et al., in Togo, who found an anemia prevalence of $88.9 \%$. Their patients were also mostly in moderate anemia [32]. However, our hemoglobin level was similar to that of Algeria [31].

Concerning platelet count, it ranged from 42,000 to $2,252,000 / \mathrm{mm}^{3}$, with a mean of 336,769. Most of our patients (42.4\%) had it between 200,000 and $400,000 / \mathrm{mm}^{3}$. It was normal for $60.6 \%$ while $32.1 \%$ had thrombocytosis. Our findings were similar to that of Mukiibi et al. and Mupepe et al. who found that most of their patients had a normal platelet count [25] [30].

Most of our patients (59.3\%) had normal basophile count. This was similar to that of Edjeme Gnaneli et al., who found normal basophile count in $77 \%$ of his study population [33].

Standard karyotype was performed in 128 (97\%) patients, with Philadelphia chromosome ( $\mathrm{Ph} \mathrm{Chr}$ ) identified in 108 (81.8\%) patients. This was lower than Edjeme Gnaneli et al. findings (100\%) but higher than Mukiibi et al. (13.3\%) and Djouadi-Lahlou (10\%) [30] [31] [33]. The RT-PCR has been performed in 11\% of the study population in Algeria while all patients in Togo have done it [31] [32].

Other biological exams showed normal fasting blood sugar, serum creatinine, urea and GPT levels. However, biological signs of cellular necrosis, coagulation 
perturbation and an inflammatory syndrome were found. This reflects the tumoral metabolism and processes. Mupepe et al. performed in Kinshasa, uricemia (ranging from 60 to $108 \mathrm{mg} / \mathrm{L}$ ), fasting blood sugar (ranging from 50 to 172 $\mathrm{g} / \mathrm{dL}$ ) and serum creatinine (ranging from 1.2 to $4.7 \mathrm{mg} / \mathrm{dL}$ ) [25].

This study should be interpreted in light of some limitations. Most of our patients were recruited in the retrospective phase. As a result, records were not found and data was missing from some of our patients, particularly for clinical signs. On the other hand, bone marrow aspiration, abdominal ultrasound and blood film were not performed routinely in patients with CML, which are necessary to establish the prognostic score at the time of diagnosis. This is due to their expensive cost for the Cameroonian population where the minimum wage is 60.6 USD. Another pitfall of this work was the impossibility to perform a correlation between the disease phase and the biological anomalies.

\section{Conclusion}

This study described the hematobiological profile at the diagnosis of patients with CML in Cameroon. These patients presented at their diagnosis marked hyperleukocytosis and anemia as hematological clues. Other biological anomalies include increased signs of cellular destruction (uricemia, LDH,) coagulation perturbation and inflammatory syndrome. The chronic phase of the disease was common. Further prospective studies with more laboratory exams are needed as well as an improvement of the technical platform of Cameroonian laboratories in order to locally perform diagnosis tests (standard karyotype, FISH and PCR).

\section{Declarations}

\section{Ethics Approval and Consent to Participate}

This work was approved by the board of the National Committee for Human Health Research (registration number 2016/06/778/CE/CNERSH/SP), the directors of the Yaoundé University Teaching Hospital, the Yaoundé Central Hospital and the Yaoundé General hospital. This work was carried out in accordance with the declaration of Helsinki [34]. All ethical rules involving research on disadvantaged groups such as prisoners have been respected [35]. Patients were free to attend the study without any outside constraint. We obtained informed and signed consent forms from each participant recruited in the prospective phase.

\section{Acknowledgements}

None.

\section{Authors' Contributions}

Conception and Design: APBN, PN, CTT, DM. Drafting of the manuscript: SRSN, PAT, APBN, PN, CTT, DM. Reviewing Manuscript: PN, CTT, DM. All the authors read and approved the final draft for publication. 


\section{Conflicts of Interest}

The authors declare no conflicts of interest regarding the publication of this paper.

\section{References}

[1] Savage, D.G., Szydlo, R.M. and Goldman, J.M. (1997) Clinical Features at Diagnosis in 430 Patients with Chronic Myeloid Leukaemia Seen at a Referral Centre over a 16-Year Period. British Journal of Haematology, 96, 111-116. https://doi.org/10.1046/j.1365-2141.1997.d01-1982.x

[2] Leguay, T. and Mahon, F.-X. (2006) Leucémie Myéloïde Chronique. EMC-Hématologie, 16, 1-13.

[3] Granatowicz, A., Piatek, C.I., Moschiano, E., El-Hemaidi, I., Armitage, J.D. and Akhtari, M. (2015) An Overview and Update of Chronic Myeloid Leukemia for Primary Care Physicians. Korean Journal of Family Medicine, 36, 197-202. https://doi.org/10.4082/kjfm.2015.36.5.197

[4] Sant, M., Allemani, C., Tereanu, C., De Angelis, R., Capocaccia, R., Visser, O., et al. (2010) Incidence of Hematologic Malignancies in Europe by Morphologic Subtype: Results of the HAEMACARE Project. Blood, 116, 3724-3734. https://doi.org/10.1182/blood-2010-05-282632

[5] Delord, M., Foulon, S., Cayuela, J.-M., Rousselot, P. and Bonastre, J. (2018) The Rising Prevalence of Chronic Myeloid Leukemia in France. Leukemia Research, 69, 94-99. https://doi.org/10.1016/j.leukres.2018.04.008

[6] Smith, A., Howell, D., Patmore, R., Jack, A. and Roman, E. (2011) Incidence of Haematological Malignancy by Sub-Type: A Report from the Haematological Malignancy Research Network. British Journal of Cancer, 105, 1684-1692. https://doi.org/10.1038/bjc.2011.450

[7] Chen, Y.M., Wang, H.J., Kantarjian, H. and Cortes, J. (2013) Trends in Chronic Myeloid Leukemia Incidence and Survival in the United States from 1975 to 2009. Leukemia \& Lymphoma, 54, 1141-1147. https://doi.org/10.3109/10428194.2012.745525

[8] American Cancer Society (2018) Cancer Facts \& Figures 2018. https://www.cancer.org/research/cancer-facts-statistics/all-cancer-facts-figures/canc er-facts-figures-2018.html

[9] Faye, B.F., Dieng, N., Seck, M., Gadji, M., Gueye, Y.B., Sy, D., et al. (2016) Pattern of Chronic Myeloid Leukemia in the Imatinib Era in a Sub-Saharan African Setting. Annals of Hematology, 95, 1603-1610. https://doi.org/10.1007/s00277-016-2745-4

[10] Koffi, K.G., Nanho, D.C., N'dathz, E., Kouehion, P., Dissieka, R., Attia, A., et al. (2010) The Effect of Imatinib Mesylate for Newly Diagnosed Philadelphia Chromosome-Positive, Chronic-Phase Myeloid Leukemia in Sub-Saharan African Patients: The Experience of Côte d'Ivoire. Advances in Hematology, 2010, Article ID: 268921. https://doi.org/10.1155/2010/268921

[11] Nanho, D.C., N’Diaye, F.S., Tolo, A., Kouamenan, G.S., Sekongo, Y.M., Ayemou, R., et al. (2008) Is Hepatomegaly a Prognosis Factor of Chronic Myeloid Leukaemia among African Blacks? Mali Medical, 23, 19-22.

[12] Gaudong Mbethe, G.L., Mounguengui, D., Magne, C., Ondounda, M., Yboutsi, L., Ibaba, J., et al. (2016) Assessment of Imatinib in the Treatment of Chronic Myeloid Leukemia in Gabon: A Cohort of 17 Cases. Médecine et Santé Tropicales, 26, 184-188. https://doi.org/10.1684/mst.2016.0547 
[13] Boma, P.O., Durosinmi, M.A., Adediran, I.A., Akinola, N.O. and Salawu, L. (2006) Clinical and Prognostic Features of Nigerians with Chronic Myeloid Leukemia. $\mathrm{Ni}$ gerian Postgraduate Medical Journal, 13, 47-52.

[14] Silué, D.A., Kouakou, B., Nanho, C.D., Kamara, I., Djoko, S., Sowhe, T., et al. (2019) Caractéristiques Préthérapeutiques et Évolutives des Patients Atteints de la Leucémie Myéloïde Chronique à Abidjan Côte d'Ivoire. Bulletin du Cancer, 106, 550-559. https://doi.org/10.1016/j.bulcan.2019.03.013

[15] Ngock Dime, P.A., Chetcha Chemegni, B., Tayou Tagne, C., Nlend Nlend, M.C., Ngouadjeu, E., Ngo Sack, F, et al. (2016) La Réponse Hématologique chez les Patients Atteints de Leucémie Myéloïde Chronique sous Imatinib à Yaoundé. Health Sciences and Diseases, 17, 1-6.

[16] Chetcha Chemegni, B., Menanga, J.C.E., Atenguena, E., Ngouadjeu, E., Sack, F.N., Tagne, C.T., et al. (2018) Comorbidités chez les Patients Atteints de Leucémie Myéloïde Chronique à Yaoundé. Health Sciences and Diseases, 19, 63-65.

[17] Moueleu Ngalagou, P.T., Ngouadjeu Dongho Tsakeu, E., Ngo Sack, F., Eboumbou Moukoko, E.C., Konn Jolly, Y. and Luma, H. (2018) Epidemiology of Malignant Hemopathies Recorded in Hospitals in Cameroon. Médecine et Santé Tropicales, 28, 61-66. https://www.jle.com/10.1684/mst.2018.0759

[18] Takouchop (2001) Efficacite de l'Imatinib dans le Traitement de la Leucemie Myeloide Chronique au Cameroun. Université de Yaoundé I, Yaounde.

[19] Chetcha Chemegni, B., Nlend, M.N., Dime, P.N. and Ndom, P. (2016) Survie des Patients Atteints de Leucémie Myéloïde Chronique sous Traitement par Imatinib à Yaounde. Health Sciences and Diseases, 17, 81-86.

[20] Işik, H. and Ndifusah, H. (2013) Health Care System and Health Financing Structure, the Case of Cameroon. International Anatolia Academic Online Journal Health Sciences, 1, 24-44.

[21] Chetcha Chemegni, B., Menanga, J.C.E., Atenguena, E., Ngouadjeu, E., Sack, F.N., Tagne, C.T., et al. (2018) Comorbidités chez les Patients Atteints de Leucémie Myéloïde Chronique à Yaoundé. Health Sciences and Diseases, 19, 63-65.

https://www.hsd-fmsb.org/index.php/hsd/article/view/933

[22] Oyekunle, A.A., Bolarinwa, R.A., Oyelese, A.T., Salawu, L. and Durosinmi, M.A. (2015) Determinants of Overall and Progression-Free Survival of Nigerian Patients with Philadelphia-Positive Chronic Myeloid Leukemia. Advances in Hematology, 2015, Article ID: 908708. https://doi.org/10.1155/2015/908708

[23] Ben Lakhal, R., Ghedira, H., Bellaaj, H., Ben Youssef, Y., Menif, S., Manai, Z., et al. (2018) Chronic Myeloid Leukemia Patients in Tunisia: Epidemiology and Outcome in the Imatinib Era (a Multicentric Experience). Annals of Hematology, 97, 597-604. https://doi.org/10.1007/s00277-017-3224-2

[24] Segbena, A.Y., Kueviakoe, I.M.D., Agbetiafa, K., Padaro, E., Layibo, Y., Dorkenoo, A., et al. (2012) Chronic Myeloid Leukemia and Imatinib: Experience at the Lome Campus Teaching Hospital (Togo). Médecine et Santé Tropicales, 22, 307-311. https://doi.org/10.1684/mst.2012.0083

[25] Mupepe, M., Ngwala, D., Kabengele, O. and Mpwate, K. (2013) Profil Épidémioclinique, Aspects Thérapeutiques et Évolutifs de la Leucémie Myéloïde Chronique aux Cliniques Universitaires de Kinshasa Chronic Myeloid Leukemia, Epidemiology, Clinical Features, and Treatment at the Kinshasa University Hospital. Annales Africaines de Médecine, 6, 1-6.

https://anafrimed.net/profil-epidemioclinique-aspects-therapeutiques-et-evolutifs-d e-la-leucemie-myeloide-chronique-aux-cliniques-universitaires-de-kinshasa-chroni 
c-myeloid-leukemia-epidemiology-clinical-features-and-t/

[26] Utuama, O., Mukhtar, F., Pham, Y.T.-H., Dabo, B., Manani, P., Moser, J., et al. (2019) Racial/Ethnic, Age and Sex Disparities in Leukemia Survival among Adults in the United States during 1973-2014 Period. PLOS ONE, 14, e0220864. https://doi.org/10.1371/journal.pone.0220864

[27] Lee, J.P., Birnstein, E., Masiello, D., Yang, D. and Yang, A.S. (2009) Gender and Ethnic Differences in Chronic Myelogenous Leukemia Prognosis and Treatment Response: A Single-Institution Retrospective Study. Journal of Hematology \& Oncology, 2, Article No. 30. https://doi.org/10.1186/1756-8722-2-30

[28] Mendizabal, A.M., Garcia-Gonzalez, P. and Levine, P.H. (2013) Regional Variations in Age at Diagnosis and Overall Survival among Patients with Chronic Myeloid Leukemia from Low and Middle Income Countries. Cancer Epidemiology, 37, 247-254. https://doi.org/10.1016/j.canep.2013.01.002

[29] Höglund, M., Sandin, F. and Simonsson, B. (2015) Epidemiology of Chronic Myeloid Leukaemia: An Update. Annals of Hematology, 94, S241-S247.

https://doi.org/10.1007/s00277-015-2314-2

[30] Mukiibi, J.M., Nyirenda, C.M., Paul, B., Adewuyi, J.O., Mzula, E.L.B. and Malata, H.N. (2003) Chronic Myeloid Leukaemia in Central Africans. East African Medical Journal, 80, 470-475. http://journals.uonbi.ac.ke/eamj/article/view/584 https://doi.org/10.4314/eamj.v80i9.8744

[31] Djouadi-Lahlou, K. (2010) Etude Epidemiologique Nationale de la Leucemie Myeloîde Chronique en Algerie: Travail Coopératif et Multicentrique sur une Période de 16 ans. A Propos 1927 Cas (1994-2009). Revue Algérienne d Hématologie, 3, 6-10.

[32] Messanh Kueviakoe, I., Agbetiafa, K., Padaro, E., Layibo, Y., Kolou, M., Amavi, T. and Segbena, A. (2015) Profil Evolutif des Patients Souffrant de Leucemie Myeloïde Chronique Sous Imatinib au Togo: Etude de 63 Cas Colliges en 10 ans au Chu-Campus de Lome. Journal de la Recherche Scientifique de P Université de Lomé, 16, 473-482.

[33] Edjeme Gnagneli, L.W. (2008) La Classification de Tura dans la Leucemie Myeloide Chronique: Impact Pronostique. Université de Bamako, Faculté de Médecine, de Pharmacie et D'Odontostomatologie, Bamako.

[34] Association Médicale Mondiale (2013) Déclaration d'Helsinki de l'Association Médicale Mondiale-Principes Éthiques Applicables À la Recherches Médicales sur des Êtres Humains.

https://www.wma.net/fr/policies-post/declaration-dhelsinki-de-lamm-principes-eth iques-applicables-a-la-recherche-medicale-impliquant-des-etres-humains/

[35] World Health Organization and Council for International Organizations of Medical Sciences (2017) International Ethical Guidelines for Health-Related Research Involving Humans. Council for International Organizations of Medical Sciences, Geneva. 


\section{List of Abbreviations}

ACS: American Cancer Society

AP: Accelerate Phase

BC: Blast Crisis

CML: Chronic myeloid leukemia

$\mathrm{CP}$ : Chronic phase

ELN: European leukemia Net

ET: Essential thrombocythemia

LMIC: Low- and middle-income countries

PMF: Primary myelofibrosis

SOCHIMIO: Solidarité Chimiothérapie

SSA: Sub-Saharan Africa

USA: United States of America

TKI: Tyrosine kinase inhibitor

VD: Vasquez's disease

WHO: World Health Organization

YGH: Yaoundé General Hospital 